\title{
Research Methodology Training for First Year Postgraduate Residents: Perception of the Participants at Kirkpatrick Level One
}

\author{
Piryani Rano Mal ${ }^{1 *}$, Piryani Suneel ${ }^{2}$ and Kafle Raju ${ }^{3}$ \\ ${ }^{1}$ Professor of Internal Medicine and Head of Department of Internal Medicine and Chief Coordinator-Health Professions Training \\ Committee, Universal College of Medical Sciences, Bhairahawa \\ ${ }^{2}$ Research Specialist, Department of Community Health Sciences, Aga Khan University, Pakistan \\ ${ }^{3}$ Associate Professor of Pediatrics, Research Training Coordinator, Universal College of Medical Sciences, Bhairahawa
}

*Corresponding author: Piryani Rano Mal, Professor of Internal Medicine and Head of Department of Internal Medicine, Chief Coordinator-Health Professions Training Committee, Universal College of Medical Sciences, Bhairahawa, Nepal

\section{ARTICLE INFO}

Received: 幽 November 12, 2019

Published: 幽 November 19, 2019

Citation: Piryani Rano Mal, Piryani Suneel, Kafle Raju. Research Methodology Training for First Year Postgraduate Residents: Perception of the Participants at Kirkpatrick Level One. Biomed J Sci \& Tech Res 23(1)-2019. BJSTR. MS.ID.003837.

Keywords: Feedback; Perception; Reaction; Residents; Research; Training

\begin{abstract}
\section{Background}

Postgraduate residents have to prepare synopsis for conducting research to develop thesis as pre-requisite to appear Tribhuvan University qualifying examination for MD/ MS/MDS/MN. Undertaking research is one of the competencies resident has to acquire during training. For serving the purpose Universal College of Medical Sciences (UCMS), Bhairahawa organized one-day research methodology training for first-year residents on June 11, 2019. The objective of this study was to take feedback of participant residents and assess their reaction/perception at Kirkpatrick level one.
\end{abstract}

\section{Methods}

Feedback of the participant was taken on valid semi-structured questionnaire comprised of four parts: demographic information, overall feedback on training, feedback on specific sessions and feedback for improvement. Data analysis was done using SPSS version 21.

\section{Results}

The participants rated training on scale 1-10 (1=poor, 10=excellent) regarding usefulness (8.20 \pm 1.55$)$, content $(7.68 \pm 1.18)$, relevance $(7.96 \pm 1.60)$, facilitation $(7.56 \pm 1.22)$, interactive teaching/learning $(7.16 \pm 1.65)$, research skills development $(7.32 \pm 1.31)$ and overall $(7.60 \pm 1.25)$. Participants' reaction/perception on specific sessions conducted in training rated on Likert scale 1-4 (4=Strongly agree, 1=Not agree) was notable; "Essential of Research Protocol" (3.16 \pm 0.62$)$, "Identifying Research Question" (3.04 \pm 0.61$)$, "Literature Review" (3.32 \pm 0.55$)$, "Online Demonstration for Literature Review" (3.48 \pm 0.58$)$, "Medical Research Methodology" (3.44 \pm 0.65$)$, "Taking consent in research and ethics in research" (3.48 \pm 0.58$)$, and "Applied Basic Statistics" (3.28 \pm 0.67$)$. Two participants mentioned that "Learnt so many aspects of research I had no idea about them before". They suggested to increase duration of workshop for better learning about subject and doing practice for writing synopsis for thesis.

\section{Conclusion}

The reaction/perception of participants was positive and constructive. Their suggestion to increase duration of training was valid. 


\section{Introduction}

A research methodology training is a crucial to develop capacity of future healthcare professionals with art of research skills [1]. Residents are prospective healthcare professionals, so, developing capacity of postgraduate residents in undertaking research is vital. Conducting research is among the core competencies of residency program. It enriches analytic and critical thinking skills of resident, promote lifelong learning and foster evidence-based medicine practice and quality patient care [2]. The thesis submission to Tribhuvan University Institute of Medicine (TU-IOM) Kathmandu Nepal is mandatory as a partial fulfillment to each postgraduate (PG) resident of all subjects who perusing Doctor of Medicine (MD), Master of Surgery (MS), Master of Dental Surgery (MDS) and Master of Nursing (MN) courses before appearing in final qualifying examination. Hence, each PG has to conduct research for thesis. They have to submit research synopsis (proposal) during first year of residency [3,4]. UCMS is affiliated with TU-IOM running postgraduate courses in medicine, dentistry, nursing and allied sciences [5]. A one-day workshop in research methodology was conducted for new batch of first year MD/MS/MDS/MN residents at Universal College Medical College of Sciences (UCMS) Bhairahawa Nepal. The feedback from the participant residents is critical to make necessary changes in content, methodology, duration and process of workshops to be conducted in future for incoming batches of PG residents [6]. The objective of this study was to take feedback of the participant residents and assess reaction/ perception of the participants at Kirkpatrick level one.

\section{Methodology}

A one-day "Research Methodology Training for First Year Postgraduate Residents” was conducted on June 11, 2019 at Universal College of Medical Sciences (UCMS) Bhairahawa, Nepal. It was of 8 working hours and 3.75 credit points was awarded by Nepal Medical Council for this training. Twenty-eight residents participated in training; sixteen from clinical sciences, five from basic sciences, five from dentistry and two from nursing. Six resource persons from UCMS conducted sessions in training. The sessions conducted were:

1. Essential of Research Protocol,

2. Identifying Research Question including making hypothesis and process in thesis writing,

3. Literature Review including citation and referencing,

4. Online Demonstration for Literature Review including approaching the site for search,

5. Medical Research Methodology including designing methods for specific studies,

6. Taking consent in research and ethics in research, and

7. Applied Basic Statistics including sample technique and sample size calculation.
Tutorial, brainstorming and demonstration were the methods utilized for training.

The objective of this study was to take feedback from the participant residents and assess how they react/perceive the training at level-I of Kirkpatrick model of evaluation. Kirkpatrick model of evaluation has four levels: Level I: Reaction, Level 2A: Learning-change in attitude, Level 2B: Learning-modification of knowledge and skills, Level 3: Behavior-change in behavior, Level 4A: Results: change in the system or organizational practice and Level 4B: Results-change among the participants' students and peers [7]. At the end of training workshop, feedback of the participant residents was taken on the valid semi-structured questionnaire comprised of four parts.

\section{Part A. Demographic Information}

Info was taken on age in years, sex, year of graduation and any training related to research received before.

\section{Part B. Overall Feedback on Training}

This part contained two close ended questions; one was on rating training on scale 1-10 (1=poor, 10=excellent) for usefulness, content, relevance of session and content, facilitation, interactive teaching/learning, research skills development and training as overall; while another was whether this training has transformed you a good researcher on Likert Scale 1-4 (4=Strongly agree, 3 =Fairly agree, $2=$ =Slightly agree, $1=$ =Not agree).

\section{Part C. Feedback on Specific Sessions}

This part covered seven closed ended questions on rating specific sessions conducted in training. The questions were on: "Essential of Research Protocol", "Identifying Research Question", "Literature Review", "Online Demonstration for Literature Review”, "Medical Research Methodology", "Taking consent in research and ethics in research", and "Applied Basic Statistics" and rated on Likert scale 1-4 (4=extremely Important, 3=moderately important, 2=slightly important, $1=$ not important).

\section{Part D. Feedback for Improvement}

This part had three open ended questions; one was on good points/strengths of training, second on areas for improvement and third for additional comments.

The informed consent was taken from the participants and ethical approval was obtained from institutional review committee of UCMS. The data collected was checked for completeness, accuracy and consistency. It was entered in IBMS SPSS version 21 for analysis. Descriptive analysis was done; the frequency, mean and standard deviation were computed.

\section{Results}

\section{Part A. Demographic Information}

Out of 28 participants, 25 consented to provide feedback; the response rate was $89.28 \%$. The age of the participant residents 
was 28.24 \pm 2.96 years (range 22-37 years); 12 were males and 13 females. Nineteen were from medicine (MBBS), 4 from dentistry (BDS) and 2 from nursing (BSc/BN). Only two participants (7\%) received training before.

\section{Part B. Overall Feedback on Training Workshop}

The participant residents rated "Research Methodology Training" on scale of 1-10 (1=poor, 10=excellent); the rating was notable (Table 1). The participant residents rating on the statement "training has transformed you a good researcher" on Likert Scale 1-4 (4=Strongly agree, 3= Fairly agree, $2=$ Slightly agree, $1=$ Not agree) was remarkable $3.36 \pm 1.63$

Table 1: Rating of the participant residents of "Research Methodology Training".

\begin{tabular}{|c|c|c|}
\hline S. No & Item & Rating (Mean \pm SD) \\
\hline 1a. & Usefulness (Scale 1-10) & $8.20 \pm 1.55$ \\
\hline 1b. & Content (Scale 1-10) & $7.68 \pm 1.18$ \\
\hline 1c. & $\begin{array}{c}\text { Relevance of session \& content (Scale } \\
1-10)\end{array}$ & $7.96 \pm 1.60$ \\
\hline 1d. & Facilitation (Scale 1-10) & $7.56 \pm 1.22$ \\
\hline 1e & Interactive teaching/learning & $7.16 \pm 1.65$ \\
\hline 1f & Research skills development & $7.32 \pm 1.31$ \\
\hline 1g. & Overall (Scale 1-10) & $7.60 \pm 1.25$ \\
\hline
\end{tabular}

\section{Part C. Feedback on Specific Sessions}

The rating of the participant residents on specific sessions conducted in "'Research Methodology Training" was noteworthy (Table 2).

Table 2: Rating of the participant residents on specific sessions conducted in "“Research Methodology Training".

\begin{tabular}{|c|c|c|}
\hline S. No & Item & Rating (Mean \pm SD) \\
\hline 3 & $\begin{array}{c}\text { Rate session on "Essentials of } \\
\text { Research Protocol" conducted in } \\
\text { training on Likert scale 1-4? }\end{array}$ & $3.16 \pm 0.62$ \\
\hline 4 & $\begin{array}{c}\text { Rate session on "Identifying Research } \\
\text { Question" conducted in training on } \\
\text { Likert scale 1-4? }\end{array}$ & $3.04 \pm 0.61$ \\
\hline 5 & $\begin{array}{c}\text { Rate session on “"Literature Review" } \\
\text { conducted in training on Likert scale } \\
1-4 ?\end{array}$ & $3.32 \pm 0.55$ \\
\hline 6 & $\begin{array}{c}\text { Rate session on "Online } \\
\text { demonstration for literature review" } \\
\text { conducted in training on Likert scale } \\
1-4 ?\end{array}$ & $3.48 \pm 0.58$ \\
\hline 7 & $\begin{array}{c}\text { Rate session on "Research } \\
\text { Methodology" conducted in training on } \\
\text { Likert scale 1-4? }\end{array}$ & $3.44 \pm 0.65$ \\
\hline 8 & $\begin{array}{c}\text { Rate session on "Taking Consent in } \\
\text { Research and Ethics in Research" } \\
\text { conducted in training on Likert scale } \\
1-4 ?\end{array}$ & $3.48 \pm 0.58$ \\
\hline 9 & $\begin{array}{c}\text { Rate session on "Applied Basic } \\
\text { Statistics" conducted in training on } \\
\text { Likert scale 1-4? }\end{array}$ & $3.28 \pm 0.67$ \\
\hline
\end{tabular}

\section{Part D. Feedback for Improvement}

The strengths/good points of workshop shared by the participants were: training covered all topics related to research methodology, preparation of questionnaire, protocol development, aspects related to thesis, good examples, understandable language, interactive sessions, two-way communication, online demonstration how to access to journal, certificate with credit hours. Two participants mentioned that "Learnt so many aspects of research I had no idea about them before". The suggestions were: to increase duration of workshop for better learning about subject and doing practice especially for understanding bioethics and writing synopsis for thesis, cover session in time, provide short breaks in between sessions, conduct more such type of trainings, and make training more interactive. The Additional comments were training lent satisfaction, resource persons were really resourceful.

\section{Discussion}

The present study was conducted to take feedback of the participant residents and assess reaction/perception of the participants at Kirkpatrick level one. The participants rating was remarkable on scale 1-10 (1=poor, 10=excellent) regarding usefulness of training, content of training, relevance of sessions \& content, facilitation by resource persons, interactive teaching/ learning, research skills development and overall. Participants perceived that training have transformed them good researcher. Participants immediate reaction on specific sessions "Essential of Research Protocol”, "Identifying Research Question", "Literature Review", "Online Demonstration for Literature Review", "Medical Research Methodology", "Taking consent in research and ethics in research", and "Applied Basic Statistics" rated on Likert scale 1-4 (4=Strongly agree, $1=$ Not agree) was very positive. The findings of this study are consistent with findings of studies conducted by Bidwe $\mathrm{S}$ et al. Domple VK et al. and Alfakih AH [6,8,9]. The participant residents mentioned training covered all topics related to research methodology.

Two participants mentioned that "Learnt so many aspects of research I had no idea about them before". This finding consists with the findings of studies done by Bidwe S et al. \& PR Shankar et al. $[8,10]$. The participants suggested to increase duration of workshop for better learning about subject and doing practice especially for understanding bioethics and writing synopsis for thesis. This is a constructive feedback, hence, there is need for improvement in training. Even after three days research methodology workshop for postgraduate students, Domple VK et al. [6] mentioned about scope of improvement in sessions like literature search, hands on literature search in their study titled "Feedback of postgraduate students about research methodology workshop" [6]. The limitations of this study are that it was conducted at one institution involving a limited number of trainees and only assessed reaction/ perception of the participants immediate after the training but not 
its long-term impact of training. Thus, more research is required on the long-term effectiveness of research training.

\section{References}

1. Al Tannir M, Abu Shaheen A, Alsumaih S, AlMukaibil NF, AlHarbi R, et al. (2018) Research Knowledge and Skills Among Medical and Allied Health Students Attending a Summer Research Course: A Pretest and Posttest Analysis. Cureus 10(8): 3132.

2. Satav PJ, Wankhede UN (2017) Knowledge, attitude, and practice of resident doctors about medical research in BJ Medical College, Pune, Maharashtra. Int J Reprod Contracept Obstet Gynecol 6(7): 2969-2972.

3. http://www.iom.edu.np/?page_id=137

4. Sharma VK (2008) Glimpses of Postgraduate Teaching Programs of Nepal. Post Graduate Medical Journal of National Academy of medical Sciences 8(1).

5. www.ucms.com.np

6. Domple VK, Hiwarkar PA, Shrigiriwar MB (2019) Feedback of postgraduate students about research methodology workshop. Int J Community Med Public Health 6(1): 100-104.

ISSN: 2574-1241

DOI: 10.26717/BJSTR.2019.23.003837

Piryani Rano Mal. Biomed J Sci \& Tech Res

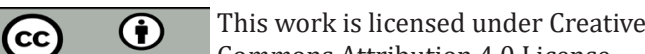

Submission Link: https://biomedres.us/submit-manuscript.php
7. Al Tannir M, Abu Shaheen A, Alsumaih S, AlMukaibil NF, AlHarbi R, et al. (2018) Research Knowledge and Skills Among Medical and Allied Health Students Attending a Summer Research Course: A Pretest and Posttest Analysis. Cureus 10(8): 3132.

8. Bidwe S, Nemade ST, Kamble CG, Powar GD (2017) Role of Research methodology workshop in improving research skills by pretest- posttest analysis. Indian Journal of Basic and Applied Medical Research 6(4): 74 77.

9. Alfakih $\mathrm{AH}$ (2017) A training program to enhance postgraduate students' research skills in preparing a research proposal in the field of curriculum and instruction methods of Arabic language. IOSR J Res Method Educ 7(3): 1-6.

10. Shankar P, Subish P, Alam K (2012) A research methodology workshop on 'Social issues in use of medicines'- cooperation between institutions and participant feedback. Journal of College of Medical Sciences-Nepal 8(1): 60-67.

$\begin{array}{ll}\text { BIOMEDICAL } & \text { Assets of Publishing with us } \\ \text { RESEARCHES } & \text { - Global archiving of articles } \\ \text { - Immediate, unrestricted online access } & \text { - Rigorous Peer Review Process } \\ & \text { - Authors Retain Copyrights } \\ \end{array}$

